\title{
ASPECTOS PETROLÓGICOS DO MAGMATISMO ALCALINO CRETÁCEO DE SANTO ANTÔNIO DA BARRA, GO
}

\author{
LÚCIA CASTANHEIRA DE MORAES*
}

\begin{abstract}
PETROLOGICAL ASPECTS OF CRETACEOUS ALKALINE MAGMATISM OF SANTO ANTÔNIO DA BARRA, GO. Mela-analcimite, olivine mela-analcimite, nepheline analcimite, phonolite, melilite mela-nephelinite, alkali basalt and basanites, both as flows and piroclastic accumulations, make up the alkaline volcanic sequence that occurs near Santo Antônio da Barra, in southwestern Goiás. Volcanism is related to the N40W Rio Verde-Iporá lineament of Cretaceous age. The volcanics show a trend of the fractional crystallization: olivine mela-analcimite $\rightarrow$ phonolite, with the mela-analcimites as the most abundant member. The relationship of rocks in this trend with melilite mela-nephelinite and basaltoid are still obscure. Petrographic and petrochemical features demonstrate the sodic/potassic mixed nature of the suite.
\end{abstract}

INTRODUÇÃo As rochas vulcânicas alcalinas de Santo Antônio da Barra foram objeto de estudo por Bez et al. (1971), Hasui et al. (1971), Gaspar (1977), Gaspar \& Danni (1981) e Moraes (1984).

Esta manifestação vulcânica ocupa uma área de mais de $400 \mathrm{~km}^{2}$ na porção sudoeste de Goiás e pode ser considerada como a facies extrusiva das manifestaçöes magmáticas que compōem o Alinhamento Tectono-magmático do Cretáceo Superior (Danni 1984), de direção noroeste. A figura 1 mostra a regiẩo estudada neste trabalho. As rochas mostram-se bem expostas em toda a área de ocorrência e, de modo geral, estão bem preservadas. Formam principalmente derrames e depósitos de brechas piroclásticas, com tufos e lapillitos subordinados, cortados por inúmeros condutos vulcânicos e diques, e foram datadas por Hasui et al. (1971) em $85 \pm 8 \mathrm{Ma}$ (método K/Ar, rocha total). Essas rochas se assentam sobre os basaltos da Formação Serra Geral e são recobertos por arenitos quartzosos cuja sedimentação se iniciou antes do final do vulcanismo: este fato é comprovado pela presença de lentes de arenito próximo ao topo da seqüência vulcânica (Fig. 2). O volume de rochas piroclásticas e a abundância de calcita e zeólitas em vênulas e amígdalas atestam o caráter fortemente explosivo do vulcanismo.

PETROGRAFIA A classificação petrográfica das rochas ígneas e dificultada por dois motivos principais: 1 . as rochas mostram sempre matriz microcristalina e/ou vítrea, o que torna difícil a identificação das diversas fases mineralogicas, em particular as félsicas, e, às veżes, impossibilita sua classificação modal; 2. a presença predominante de analcima como feldspatóide torna irreal a classificaçảo por diagramas normativos, uma vez que a analcima tem mais silica que a nefelina mas menos que a albita, minerais estes normalmente usados nos diagramas de classificaçâo.

No entanto, sua mineralogia não é muito complexa e os minerais predominantes são augita, analcima e olivina, com quantidades variáveis de feldspato potássico, plagioclásio, nefelina, flogopita e melilita. A passagem de um termo para outro é assinalada por variações de natureza e/ou abundância das fases minerais, como se verá a seguir. A presença de analcima como principal feldspatóide dessas rochas já foi objeto de estudo por Gaspar \& Danni (1979), que a caracterizaram por suas propriedades ópticas, pelo uso de raios $\mathrm{X}$ e pela composição química (análises com microssonda eletrônica). Esses autores concluíram que a analcima ê um mineral primário

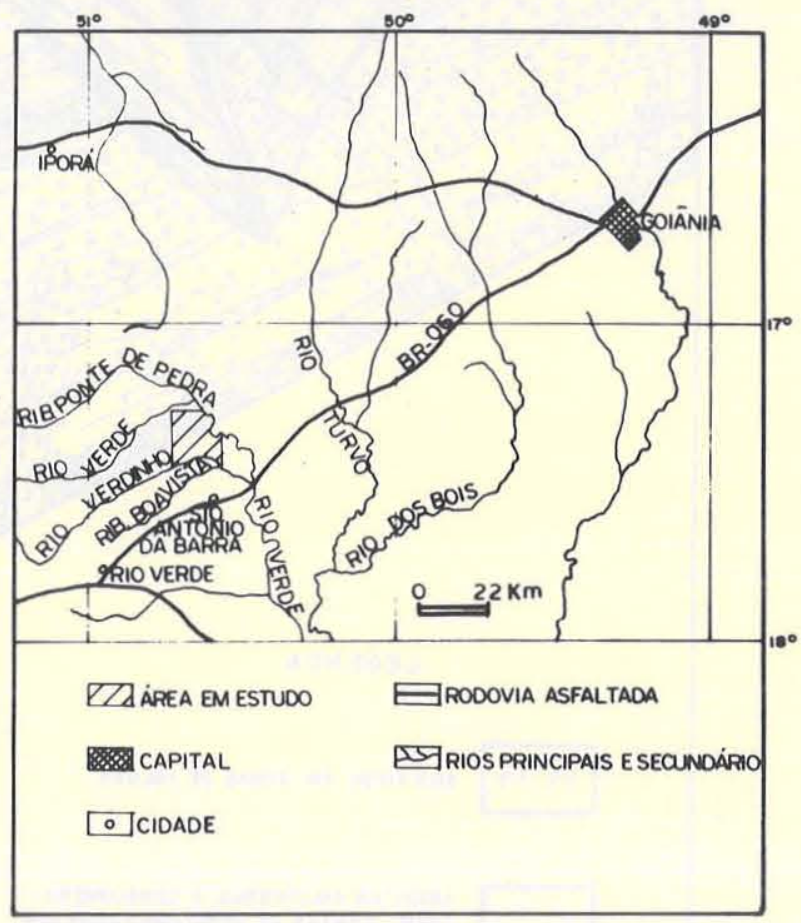

Figura 1 - Mapa de localização

nessas rochas, isto $\varepsilon$, descartaram a hipótese de atuação de um processo de analcimização na área. A prancha 1 mostra algumas feições petrográficas representativas dos termos estudados.

A classificação petrográfica segue a recomendada por Streckeisen (1980) e Le Bas (1977) e se baseia principalmente no índice de coloração e na natureza e proporção dos minerais félsicos. A tabela 1 mostra os dados modais disponíveis e os resultados normativos.

Olivina mela-analcimito $\mathrm{O}$ prefixo olivina diferencia essas rochas dos mela-analcimitos indicando possuírem mais de $10 \%$ de olivina modal. Caracterizam-se por apresentar estrutura maciça, cor cinza-escura, textura microporfiritica contendo ate $30 \%$ de fenocristais de olivina e, mais raramente, de augita. Alguns derrames såo ricos em nódulos cognatos de 


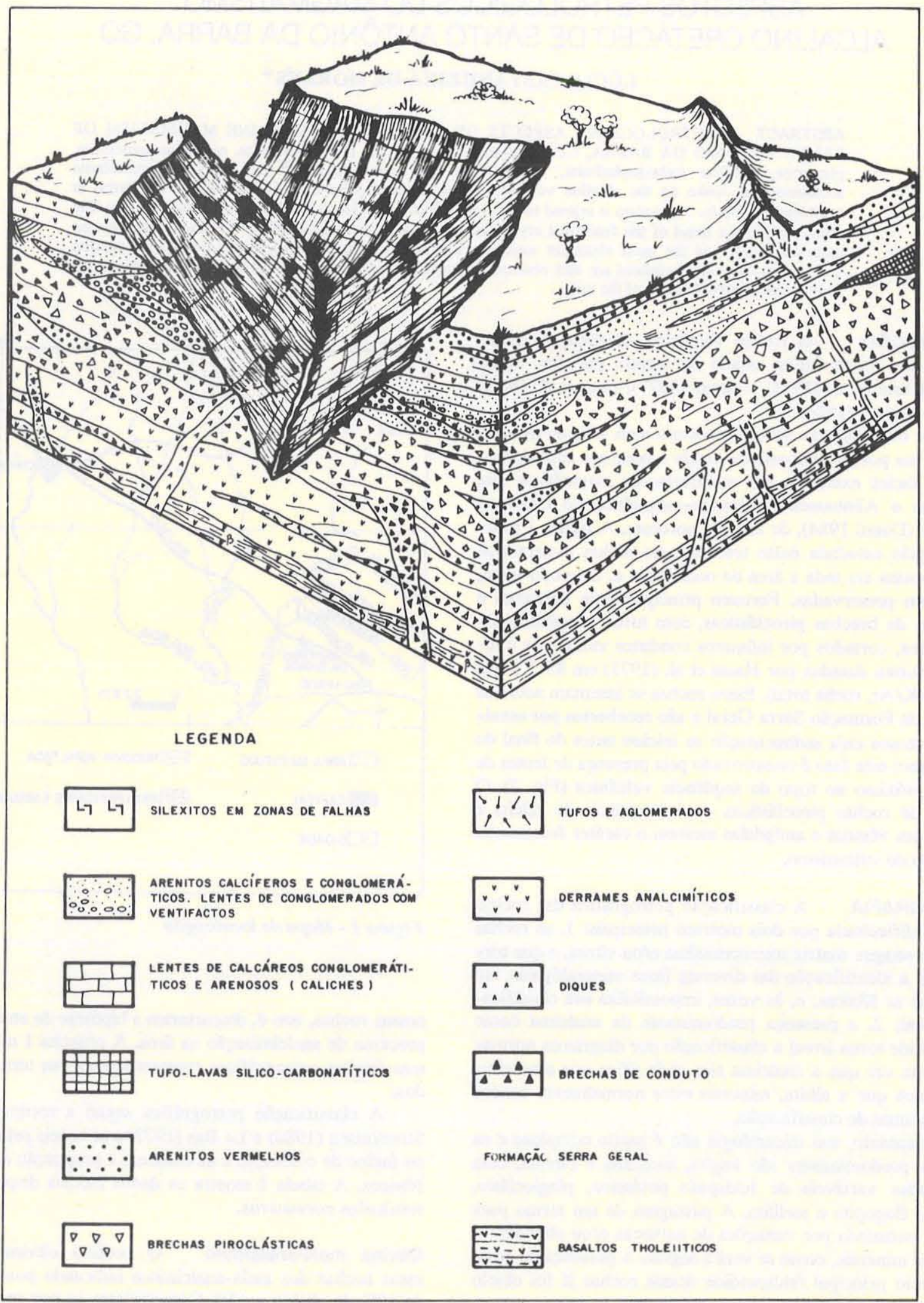

Figura 2 - Bloco-diagrama esquemático das unidades cretácicas, área de Santo Antônio da Barra (Goiás) 
olivina. Ao microsc6pio, os fenocristais de olivina se mostram parcialmente reabsorvidos e com auréolas reacionais para flogopita. A matriz é formada por uma trama de micrólitos, nos quais predomina clinopiroxênio seguido por analcima, titanomagnetita, olivina, perovskita, nefelina e cromospinélio (?).

Mela-analcimito É o termo petrográfico mais abundante na área e abriga rochas bastante variadas textural e composicionalmente, conforme se depreende da análise modal. No geral, são rochas porfiríticas com matriz afanítica a fina, de cor cinza-escuro e podem ser ricas em amígdalas preenchidas por zeбlitas e/ou carbonato. Os fenocristais são de titanaugita, analcima e olivina, e apresentam diâmetro médio de $0,3 \mathrm{~cm}$. Ao microscópio, essas rochas variam de holo a hipocristalinas. Os fenocristais de titanaugita são freqüentemente maclados e zonados, às vezes com bordos de aegirina-augita. A presença de olivina se restringe a fenocristais em proporções muito variáveis (de $1 \%$ a $8 \%$ volume). O feldspatóide típico ê a analcima, que ocorre tanto como fenocristais euédricos, formando textura glomeroporfirítica, quanto intersticialmente na matriz. A nefelina só raramente está presente e se restringe à matriz. Perovskita e titano-magnetita podem ocorrer como microfenocristais e na matriz.

Nefelina-analcimito A esta classificação correspondem rochas ricas em analcima, cujo conteúdo de minerais félsicos é superior ao de máficos. Nessas rochas, a nefelina está presente em quantidade superior a $10 \%$ na moda. Caracterizam-se por apresentar estrutura maciça, cores em tons de cinza-claro, serem ricas em aglomerados de fenocristais de analcima formando rosáceas e em amígdalas preenchidas por zeólita e/ou carbonato. Em lâmina delgada destacam-se as rosáceas de analcima e microfenocristais de nefelina e magnetita, augita, apatita, zeólitas e ilmenita. A presença de flogopita intersticial é comum. Ao contrário dos outros termos petrográficos, estas rochas normalmente apresentam alteração hidrotermal marcante na forma de oxidação, zeolitização e formação de egirina e ilvaíta.
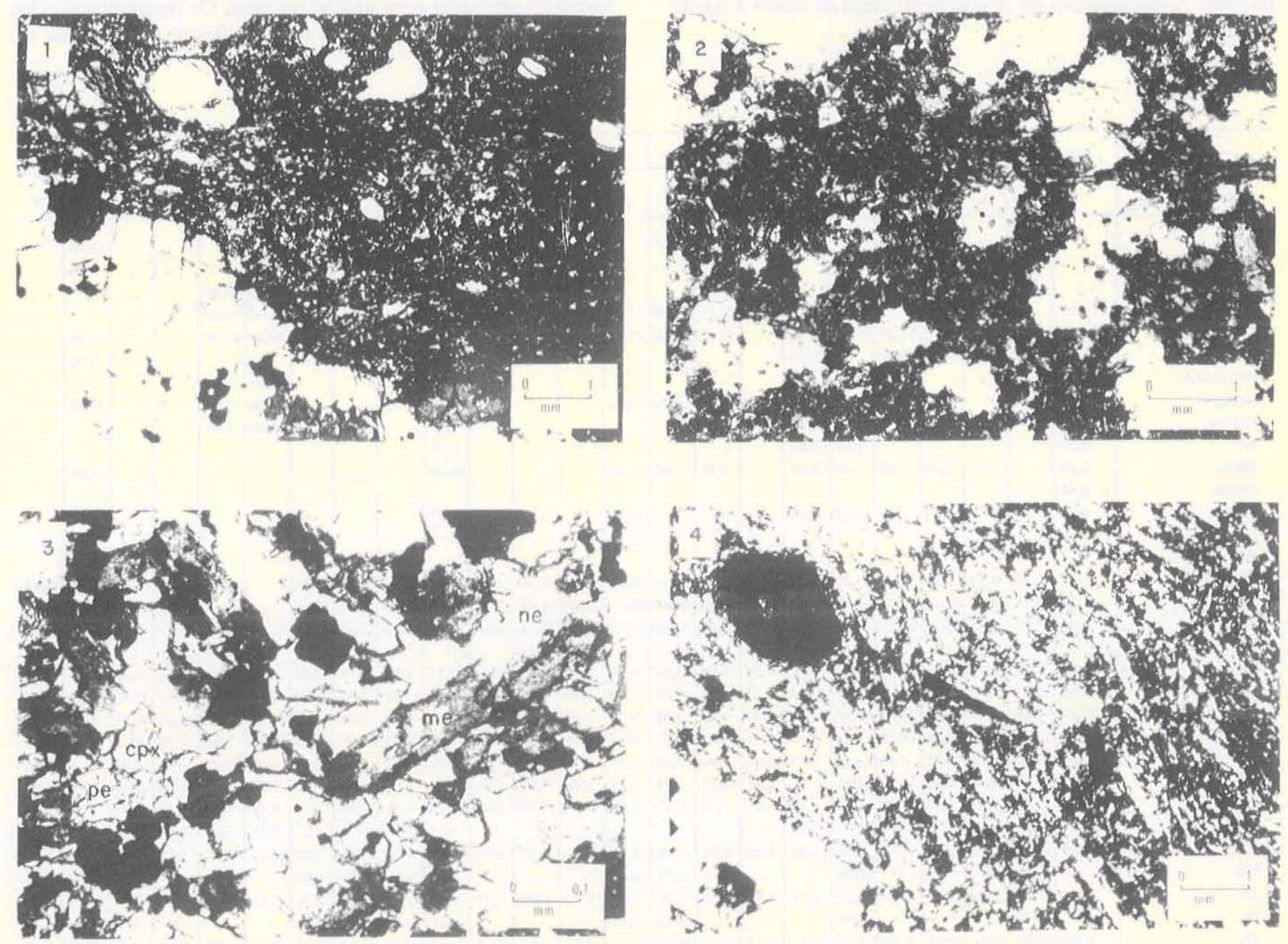

Fotomicrografia 1- - Nódulo olivinico em olivina mela-analcimito. A rocha é porfirttica. Os fenocristais de olivina acham-se em uma matriz composta basicamente por microlitos de clinopiroxênio, além de opacos, olivina e analcima. LP

Fotomicrografia 2 - Mela-analcimito; fenocristais de analcima (com inclusóes orientadas) e clinopiroxênio imersos em uma matriz fina composta de clinopiroxênio, analcima, perovskita, ilmeno-magnetita e zeolitas. LN

Fotomicrografia 3 - Matriz de melilita mela-nefelinito; os cristais tabulares alterados são de melilita (me). Ocorrem ainda clinopiroxênio (cpx), nefelina (ne), ilmeno-magnetita e perovskita (pe). LN

Fotomicrografia 4 - Textura tipica dos fonólitos. Pequenas ripas de feldspato potássico e agulhas de egirina, orientadas pelo fluxo magmático, envolvem fenocristais de feldspato potássico e augita (aqui, totalmente oxidados). LN 
Melilita melanefelinito Este termo tem ocorrência localizada. A rocha tem aspecto maciço, é afanítica com raros fenocristais de clinopiroxênio e possui cor cinza-escura. A porcentagem média de nefelina na moda é de $14 \%$ e superior à de analcima. Ao microscópio, apresenta microfenocristais de augita, perovskita, melilita, nefelina e rara olivina em uma matriz microlítica de clinopiroxênio, nefelina, perovskita, magnetita e minerais félsicos (analcima e zeбlitas?) intersticiais.

Álcali-basalto e basanito De ocorrência bastante restrita, essas rochas constituem os únicos tipos portadores de plagioclásio. Os basanitos são texturalmente maciços, afaníticos e porfiríticos (augita), e possuem quantidades variáveis de plagioclásio. Suas relações de contato com os mela-analcimitos - aos quais se associam - são muito difusas. Por outro lado, os álcali-basaltos são caracteristicamente isentos de fenocristais, são afaníticos, e muito fraturados. Em lâmina delgada, as texturas predominantes são glomeroporfirítica (microfenocristais de clinopiroxênio e minerais opacos), pilotaxítica e intersetal. A composição do plagioclásio varia de An64 a An60. A olivina é rara.
Fonólito Essas rochas $\mathrm{s} 6$ foram identificadas como componentes de lapillitos de um conduto vulcânico e como blocos em conglomerado vulcanoclástico. $\mathrm{O}$ primeiro, face à ação hidrotermal, encontra-se alterado e fortemente oxidado, com alta razão $\mathrm{Fe}_{2} \mathrm{O}_{3} / \mathrm{FeO}$. $\mathrm{O}$ segundo tipo é de granulação fina, com textura porfirítica e de fluxo marcante e cor cinza-médio. Microscopicamente, mostra fenocristais de sanidina e microfenocristais de aegirina-augita, magnetita e esfeno isolados em uma matriz muito fina, fluidal, composta de aegirina, magnetita, zeólita e nefelina. O esfeno, assim como a apatita, é acessorio.

Os dados petrográficos indicam a existência de uma série de rochas bem definidas, cujo pólo terminal é exemplificado pelos fonolitos. Os olivina mela-analcimitos representam os termos menos evoluídos. As relações entre esta série, as rochas basálticas e os melilita mela-nefelinitos não são ainda claras e necessitam de mais dados para ser definidas.

\section{ASPECTOS PETROQUÍMICOS E PETROLÓGI-} Cos Entre os diversos tipos petrográficos foram selecionadas 24 amostras para análise química. Os resultados obtidos sâo apresentados na tabela 2 , na qual foram organizados em

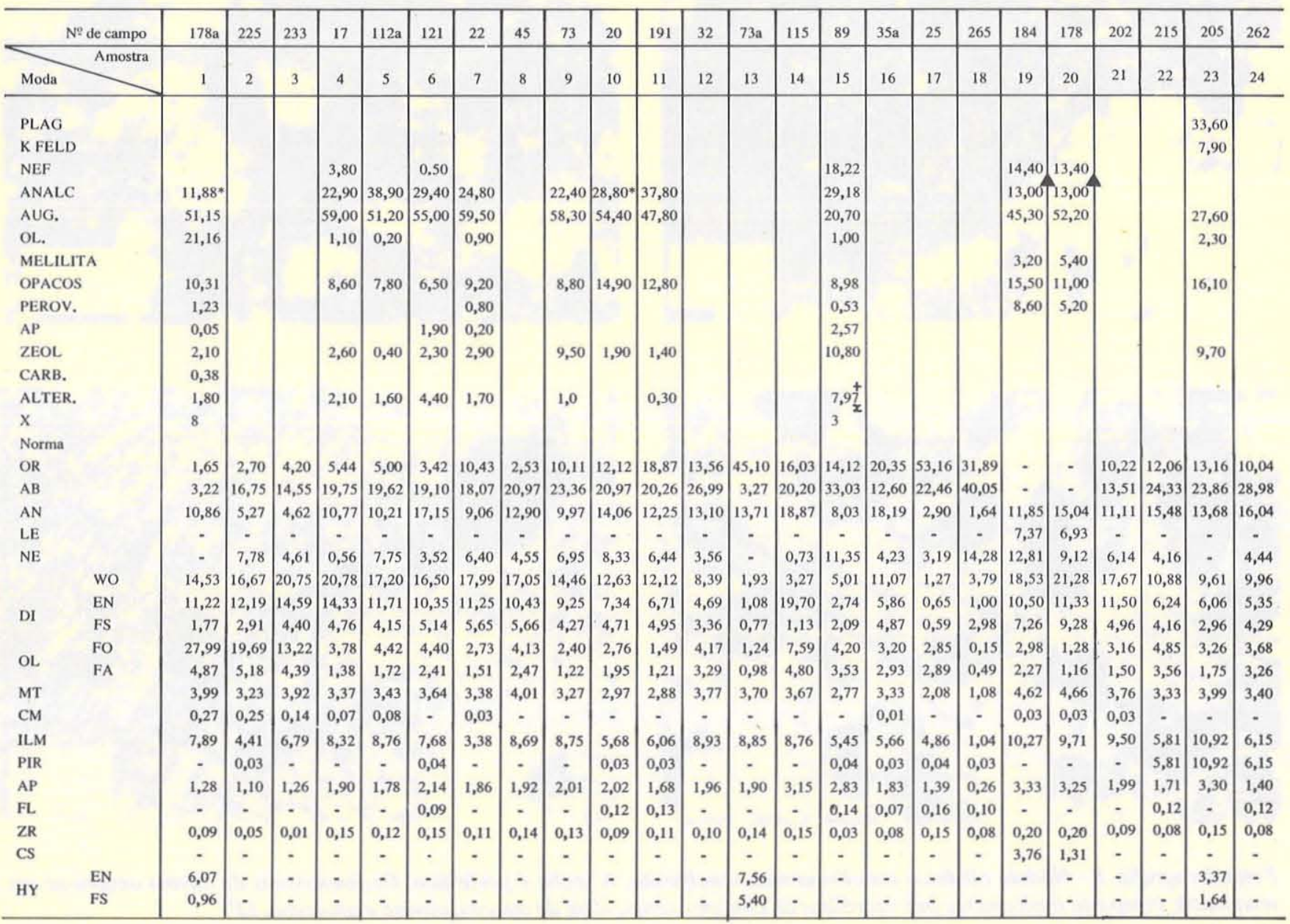

Tabela 1 - Resultados modais e normativos das rochas tgneas alcalinas de Santo Antônio da Barra, GO. Na moda, $\bar{X}$ significa número de amostras analisadas; quando não indicado, significa que a moda é da amostra em questão. * = inclui alguma nefelina; $\mathbf{\Delta}=$ inclui alguma zeólita $; x=$ biotita e minerais opacos; $+=$ carbonato. Amostras de 1 a 3 , olivina mela-analcimitos; 4 a 13, mela-analcimito; 14 a 16, nefelina analcimito; 17 e 18, fonolitos; 19 e 20, melilita mela-nefelinitos; 21 a 24, rochas basálticas 


\begin{tabular}{|c|c|c|c|c|c|c|c|c|c|c|c|c|c|c|c|c|c|c|c|c|c|c|c|c|}
\hline vedec & $178 \mathrm{a}$ & 225 & 233 & 17 & $112 \mathrm{a}$ & 121 & 22 & 45 & 73 & 20 & 191 & 32 & $73 a$ & 115 & 89 & $35 \mathrm{a}$ & 25 & 265 & 184 & 178 & 202 & 215 & 206 & 262 \\
\hline$\% \mathrm{p}$ & 1 & 2 & 3 & 4 & 5 & 6 & 7 & 8 & 9 & 10 & 11 & 12 & 13 & 14 & 15 & 16 & 17 & 18 & 19 & 20 & 21 & 22 & 23 & 24 \\
\hline $\mathrm{SiO}_{2}$ & 40,50 & 42,00 & 42,57 & 45,34 & 39,94 & 42,00 & 42,99 & 40,75 & 42,52 & 42,30 & 44,60 & 43,52 & 46,41 & 39,68 & 42,40 & 42,80 & 54,70 & 55,60 & 36,63 & 37,22 & 39,94 & 45,40 & 45,34 & 46,50 \\
\hline $\mathrm{TiO}_{2}$ & 4,20 & 2,70 & 3,89 & 4,43 & 5,29 & 4,30 & 4,27 & 4,91 & 5,22 & 3,50 & 3,60 & 4,94 & 4,58 & 4,54 & 3,60 & 3,20 & 2,70 & 0,74 & 5,37 & 5,06 & 5,61 & 3,30 & 5,73 & 3,50 \\
\hline $\mathrm{Al}_{2} \mathrm{O}_{3}$ & 4,91 & 6,60 & 5,72 & 8,88 & 9,72 & 11,30 & 9,90 & 9,95 & 11,39 & 13,40 & 13,40 & 13,16 & 13,68 & 13,68 & 15,00 & 13,80 & 16,00 & 19,30 & 10,53 & 10,30 & 9,61 & 13,60 & 12,02 & 14,60 \\
\hline $\mathrm{Fe}_{2} \mathrm{O}_{3}$ & 2,75 & 2,59 & 2,94 & 2,35 & 2,71 & 2,67 & 2,64 & 2,97 & 2,56 & 2,40 & 2,23 & 2,73 & 2,51 & 2,49 & 2,40 & 2,47 & 1,51 & 1,01 & 3,15 & 3,18 & 2,91 & 2,48 & 2,74 & 2,53 \\
\hline $\mathrm{FeO}$ & 9,76 & 9,35 & 10,60 & 8,44 & 9,74 & 9,60 & 9,50 & 10,68 & 9,21 & 8,65 & 8,05 & 9,83 & 9,03 & 8,95 & 8,64 & 8,88 & 5,43 & 3,64 & 11,34 & 11,45 & 10,46 & 8,94 & 9,87 & 9,10 \\
\hline $\mathrm{MnO}$ & 0,20 & 0,39 & 0,20 & 0,22 & 0,22 & 0,27 & 0,21 & 0,25 & 0,24 & 0,21 & 0,22 & 0,19 & 0,18 & 0,18 & 0,26 & 0,20 & 0,17 & 0,17 & 0,36 & 0,34 & 0,11 & 0,31 & 0,24 & 0,20 \\
\hline $\mathrm{MgO}$ & 22,98 & 18,80 & 14,61 & 8,01 & 8,30 & 7,10 & 6,89 & 7,04 & 5,57 & 5,30 & 4,00 & 4,49 & 4,11 & 5,06 & 4,40 & 4,50 & 2,00 & 0,66 & 5,85 & 5,23 & 7,21 & 5,70 & 5,63 & 4,60 \\
\hline $\mathrm{CaO}$ & 9,87 & 11,20 & 12,59 & 13,24 & 12,88 & 13,30 & 12,95 & 12,67 & 11,35 & 11,70 & 10,30 & 8,06 & 4,57 & 6,89 & 6,90 & 10,70 & 2,10 & 3,10 & 15,32 & 15,70 & 13,19 & 10,00 & 9,05 & 9,50 \\
\hline $\mathrm{Na}_{2} \mathrm{O}$ & 0,38 & 2,30 & 1,87 & 2,36 & 2,66 & 2,40 & 2,42 & 2,66 & 3,13 & 2,90 & 2,70 & 3,35 & 0,35 & 2,42 & 4,90 & 1,60 & 2,80 & 6,42 & 2,76 & 1,97 & 1,79 & 3,10 & 2,81 & 3,70 \\
\hline $\mathrm{K}_{2} \mathrm{O}$ & 0,28 & 0,53 & 0,74 & 0,93 & 0,97 & 0,62 & 2,00 & 0,46 & 1,94 & 2,40 & 3,60 & 2,41 & 7,50 & 2,67 & 3,00 & 3,70 & 9,49 & 7,32 & 1,57 & 1,48 & 1,94 & 2,20 & 2,22 & 2,00 \\
\hline $\mathrm{P}_{2} \mathrm{O}_{5}$ & 0,54 & 0,54 & 0,58 & 0,81 & 0,86 & 0,96 & 0,89 & 0,87 & 0,96 & 1,00 & 0,80 & 0,87 & 0,82 & 1,31 & 1,50 & 0,83 & 0,62 & 0,15 & 1,39 & 1,36 & 0,94 & 0,78 & 1,39 & 0,64 \\
\hline $\mathrm{SO}_{3}$ & - & 0,05 & - & - & - & 0,05 & - & - & - & 0,05 & 0,05 & - & - & - & 0,08 & 0,05 & 0,05 & 0,05 & - & - & - & 0,05 & - & 0,05 \\
\hline $\mathrm{BaO}$ & 0,06 & 0,16 & 0,13 & 0,31 & 0,27 & 0,32 & 0,27 & 0,17 & 0,16 & 0,23 & 0,30 & 0,21 & 0,17 & 0,23 & 0,33 & 0,22 & 0,18 & 0,18 & 0,13 & 0,25 & 0,22 & 0,28 & 0,16 & 0,17 \\
\hline P.F. & 3,27 & 2,07 & 2,86 & 4,69 & 4,66 & 4,51 & 4,96 & 4,88 & 4,47 & 4,93 & 5,42 & 4,34 & 4,28 & 8,94 & 5,72 & 6,09 & 1,48 & 1,47 & 4,18 & 5,38 & 5,45 & 3,44 & 2,29 & 2,02 \\
\hline TOTAL & 99,70 & 99,30 & 99,30 & 100,00 & 98,22 & 99,40 & 99,89 & 100,01 & 98,92 & 99,00 & 99,28 & 98,10 & 98,19 & 97,04 & 99,03 & 99,04 & 99,24 & 99,79 & 99,89 & 99,89 & 99,41 & 98,22 & 99,61 & 99,10 \\
\hline $100 . \mathrm{Mg} / \mathrm{Mg}+\mathrm{Fe}^{+2}$ & 64,60 & 60,90 & 51,70 & 42,40 & 39,80 & 36,50 & 36,00 & 34,00 & 22,50 & 32,20 & 27,90 & 26,20 & 26,10 & 30,50 & 28,30 & 28,20 & 22,20 & 12,30 & 28.60 & 26,20 & 34,80 & 33,10 & 30,90 & 28,20 \\
\hline $\mathrm{Fe}_{2} \mathrm{O}_{3} / \mathrm{FeO}$ na anÁlise & 0,48 & 1,63 & 2,51 & 1,08 & 0,91 & 1,63 & 1,80 & 1,19 & 1,17 & 2,00 & 3,23 & 1,26 & 7,60 & 2,90 & 2,24 & 2,21 & 7,76 & 1,09 & 2,50 & 1,76 & 0,55 & 1,05 & 0,70 & 1,48 \\
\hline $\mathrm{v}$ & 220 & 270 & 300 & 350 & 360 & 220 & 290 & 300 & 320 & 440 & 420 & 350 & 280 & 350 & 170 & 440 & 220 & 110 & 380 & 380 & 420 & 390 & 290 & 420 \\
\hline $\mathrm{Cr}$ & 1.500 & 1.350 & 700 & 310 & 440 & 14 & 160 & 36 & 21 & 36 & 14 & 7 & 23 & 44 & 7 & 90 & 26 & 14 & 110 & 150 & 130 & 43 & 14 & 36 \\
\hline Co & 140 & 74 & 96 & 64 & 100 & 46 & 64 & 70 & 78 & 29 & 29 & 60 & 46 & 82 & 31 & 44 & 60 & 11 & 60 & 78 & 64 & 53 & 50 & 37 \\
\hline $\mathrm{Ni}$ & 510 & 390 & 300 & 88 & 200 & 37 & 92 & 49 & 49 & 48 & 23 & 34 & 38 & 66 & 23 & 68 & 33 & 14 & 60 & 65 & 83 & 50 & 28 & 71 \\
\hline $\mathrm{Rb}$ & 17 & 32 & 40 & 98 & 59 & 72 & 93 & 68 & 67 & 120 & 110 & 150 & 120 & 220 & 71 & 160 & 110 & 190 & 94 & 50 & 150 & 85 & 35 & 22 \\
\hline Sr & 640 & 570 & 660 & 1.150 & 910 & 1.220 & 800 & 1.400 & 1.340 & 1.450 & 1.950 & 890 & 970 & 1.700 & 2.250 & 770 & L.300 & 2.300 & 2.170 & 1.700 & 670 & 1.040 & 1.420 & 1.020 \\
\hline Mo & 11 & 22 & 11 & 12 & 16 & 16 & 12 & 13 & 16 & 32 & 30 & 14 & 12 & 14 & 27 & 37 & 14 & 15 & 14 & 15 & 14 & 32 & 14 & 28 \\
\hline $\mathrm{Zr}$ & 320 & 300 & 450 & 460 & 480 & 940 & 540 & 540 & 530 & 500 & 620 & 510 & 460 & 520 & 790 & 460 & 520 & 600 & 800 & 780 & 490 & 420 & 400 & 460 \\
\hline $\mathrm{Nb}$ & 89 & 87 & 120 & 140 & 140 & 250 & 170 & 170 & 160 & 170 & 215 & 130 & 120 & 170 & 235 & 175 & 130 & 110 & 270 & 250 & 150 & 135 & 100 & 110 \\
\hline $\mathrm{Y}$ & 48 & 35 & 58 & 62 & 74 & 120 & 74 & 76 & 81 & 76 & 68 & 71 & 90 & 76 & 96 & 58 & 45 & 50 & 120 & 120 & 71 & 64 & 86 & 58 \\
\hline $\mathrm{La}$ & 100 & 80 & 190 & 210 & 260 & 460 & 210 & 360 & 300 & 310 & 410 & 240 & 260 & 360 & 430 & 430 & 140 & 370 & 450 & 480 & 210 & 250 & 140 & 130 \\
\hline $\mathrm{F}$ & - & 480 & - & - & - & 1.260 & - & - & - & 600 & 1.360 & - & - & - & 2.200 & 1.100 & 1.378 & 760 & - & - & - & 1.275 & - & 1.200 \\
\hline
\end{tabular}

Tabela 2 - Distribuição dos elementos maiores, menores e em traços nas rochas tgneas alcalinas de Santo Antônio da Barra, GO: 1 a 3, olivina mela-analcimitos; 4 a 13, mela-analcimitos; 14 a 16, nefelina analcimitos; 17 e 18, fonolitos; 19 e 20, melilita mela-analcimitos; 21 e 24, basanitos e álcali-basaltos. Elementos menores em ppm. Amostras 2, 6, 10, 11, 17, 18, 22 e 24 foram analisadas na Geosol. As demais, no Laboratório de Geoquímica do Degeo-UnB

ordem decrescente do valor de magnésio (peso \% 100. $\mathrm{Mg} / \mathrm{Mg}+\mathrm{Fe}^{+2}$ )dos olivina mela-analcimitos aos fonolitos. Conforme já se explicitou, as relações entre esta série, as rochas basálticas e os melilita mela-nefelinitos não são ainda claras e, por esse motivo, as análises químicas destas estão colocadas à parte, depois dos fonólitos. Caracteristicamente, essas rochas possuem altos valores de $\mathrm{K}_{2} \mathrm{O}, \mathrm{Na}_{2} \mathrm{O}$ e $\mathrm{CaO}$, baixos valores de $\mathrm{SiO}_{2}$, além de concentrações elevadas simultaneamente em $\mathrm{Ni}, \mathrm{Cr}, \mathrm{V}$ e em $\mathrm{Zr}, \mathrm{Nb}, \mathrm{Sr}, \mathrm{Ba}, \mathrm{Ti}, \mathrm{Rb}, \mathrm{F}$ e Terras-raras leves. Na norma, a ausência de quartzo e presença constante de feldspatóide e olivina são significativas.

Nos gráficos a seguir são apresentados, para comparação, alguns dados das suítes sódica (nefelina) e potássica (leucita) situadas ao longo do Sistema de Rifte da África Oriental e Central, porém, só serão discutidos no final.

$\mathrm{O}$ valor de $\mathrm{Mg}$ tem sido usado com critério para a identificação de magmas primários - desde que excluídas as rochas cumuladas. No entanto, o valor de $\mathrm{Mg}$ de basaltos e, principalmente, de rochas alcalinas é afetado pela oxidação do ferro antes, durante e após a erupção. Esse problema foi minimizado com o recálculo da razão $\mathrm{Fe}_{2} \mathrm{O}_{3} / \mathrm{FeO}$ para 0,27 em consonância com os trabalhos sobre rochas alcalinas de Kesson (1973), Wass \& Rogers (1980) e Lippard \& Truckle (1972). As razões $\mathrm{Fe}_{2} \mathrm{O}_{3} / \mathrm{FeO}$, originais das análises químicas, são apresentadas abaixo do valor de $\mathrm{Mg}$ (Tab. 2).
Magmas basálticos primários, em equilíbrio com o manto superior, possuem valor de $\mathrm{Mg}$ entre 67 e 77 (Kesson 1973). Le Bas (1978) considera como média uma valor de $\mathrm{Mg}$ igual a 71 para a associação carbonatito/nefelinito pobre em olivina e 74 para associação álcali-basalto/olivina nefelinito. Neste sentido, como se pode ver na Tabela 2 , nenhuma rocha analisada poderia ser considerada originária de um magma primário, mas todas já teriam sofrido forte fracionamento. Essa idéia ế reforçada pela presença comum, nos olivina mela-analcimitos, de nódulos cognatos olivínicos.

Em relação aos estágios de cristalização, o valor de $\mathrm{Mg}$ normalmente não mostra bem os resultados finais de cristalização, pois $\mathrm{Mg}$ e Fe caem muito. Mas é muito importante por mostrar as variações nos estágios intermediários que formam - tanto em volume quanto em tempo - a maior parte da consolidação magmática. A figura 3 mostra gráficos de valor de $\mathrm{Mg}$ versus 6 xidos de elementos maiores em que se observa uma variação ordenada de $\mathrm{MgO}, \mathrm{Al}_{2} \mathrm{O}_{3}, \mathrm{CaO}$ e $\mathrm{TiO}_{2}$, evidenciando um trend de diferenciação dos olivina mela-analcimitos até os fonólitos. Para os outros b́xidos, esta relação é menos visível. $\mathrm{O}$ enriquecimento $\mathrm{em} \mathrm{CaO}$ em direção aos mela-analcimitos pode estar representando não sర a cristalização predominante de clinopiroxênio como tambêm de perovskita, abundante em algumas rochas deste grupo. $\mathrm{TiO}_{2}$ tamberm mostra enriquecimento nos temos intermediários. Seu com- 


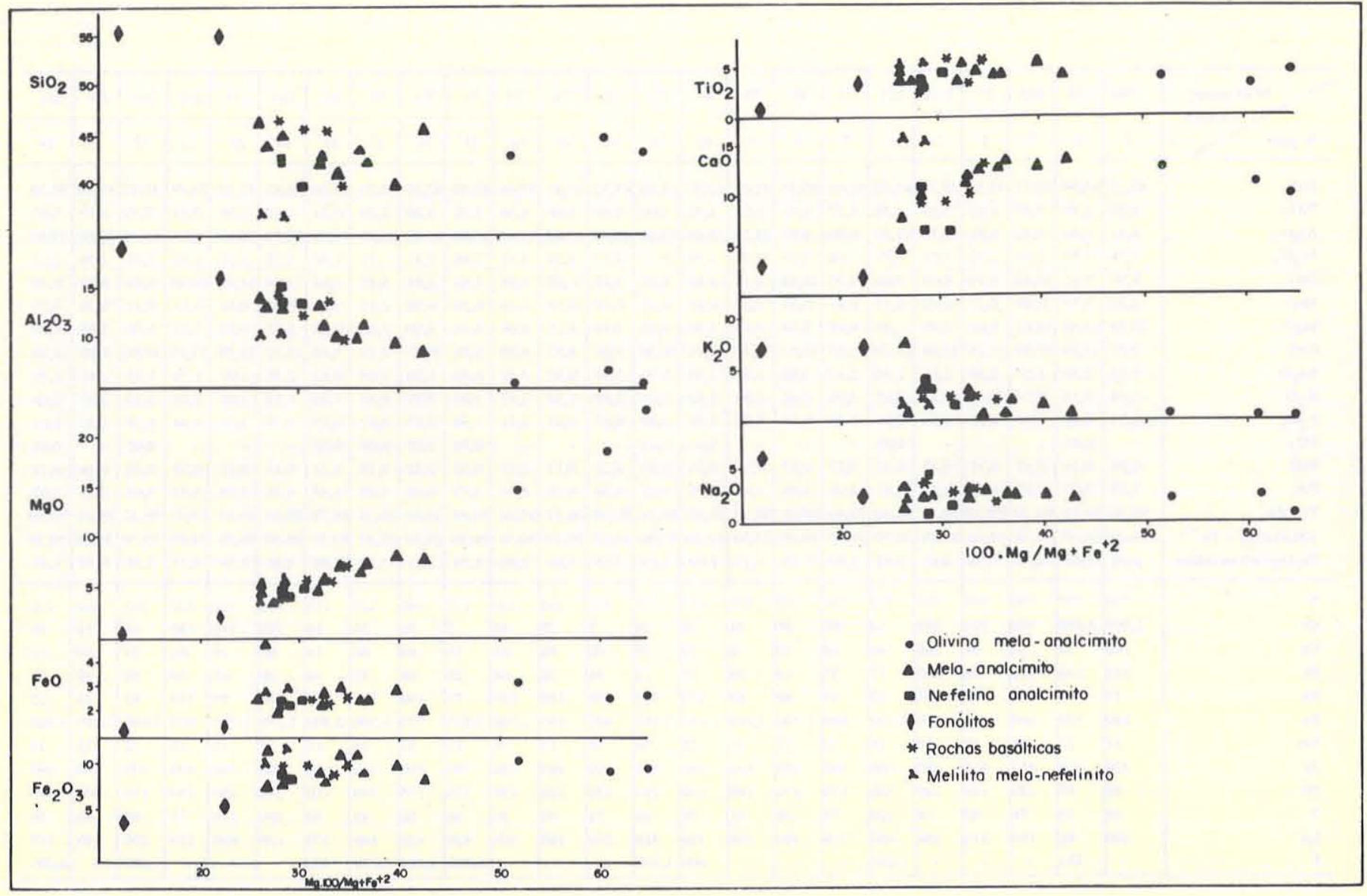

Figura 3 - Elementos maiores versus valor de magnésio

portamento, entretanto, ê mais complicado pois está presente nas rochas em pelo menos quatro fases cristalinas, a saber: titanaugita, perovskita, magnetita titanifera e esfeno. $\mathrm{Al}_{2} \mathrm{O}_{3}$ se enriquece em direção aos termos mais diferenciados nos quais se concentram feldspatoides e feldspatos. $\mathrm{SiO}_{2}, \mathrm{Na}_{2} \mathrm{O}$ e $\mathrm{K}_{2} \mathrm{O}$ mantêm-se aproximadamente constantes durante a diferenciação, mas possuem valores claramente superiores nos fonб́litos. $\mathrm{FeO}$ e $\mathrm{Fe}_{2} \mathrm{O}_{3}$ tambêm se mantêm aproximadamente constantes, mas suas curvas caem em direção aos fonolitos (menos ricos em magnetita e clinopiroxênio e sem olivina).

As rochas basálticas caem dentro do trend, de modo geral dentro do campo dos mela-analcimitos, evidenciando comportamento semelhante às outras rochas da suíte. As rochas à melilita, no entanto, mostram comportamento singular situando-se na maioria das vezes, afastadas das curvas de diferenciação. O trend pode ser visto também nas figuras $4,5,6,8$ e 9.

$\mathrm{Na}$ figura 4, o enriquecimento inicial em $\mathrm{CaO}$ confirma o importante papel dos minerais cálcicos nos mela-analcimitos. Nas fases finais, há uma queda em $\mathrm{CaO}$ acompanhada por forte enriquecimento relativo de $\mathrm{Al}_{2} \mathrm{O}_{3}$ representando, principalmente, a cristalização predominante de feldspatóides nos nefelina analcimitos e de feldspato alcalino e feldspatóide, nos fonolitos.

A disposição da curva $\mathrm{CaO} \times \mathrm{MgO}$ (Fig. 5), porém, sugere uma história magmática complexa (também obsevada em relação à curva representativa das suítes potássicas africanas);

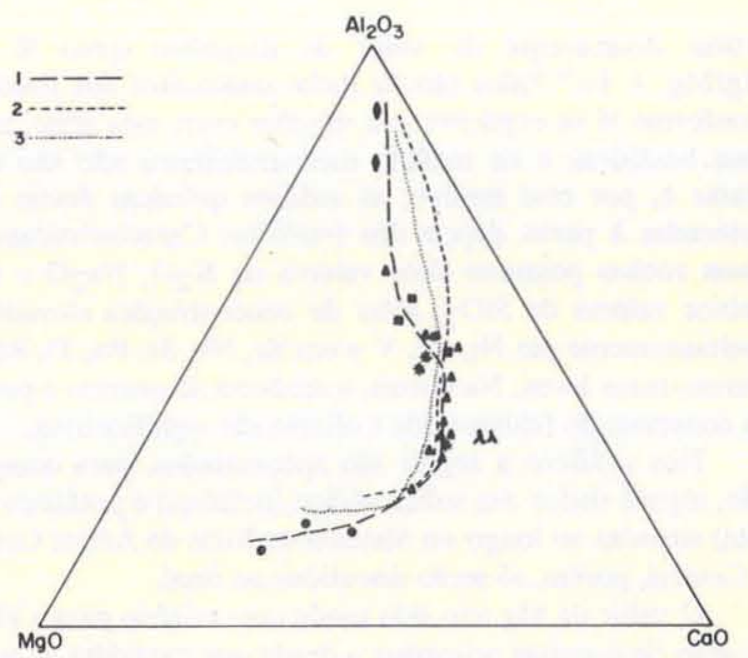

Figura 4 - Diagrama triangular $\mathrm{MgO} \times \mathrm{CaO} \times \mathrm{Al}_{2} \mathrm{O}_{3}$ (\% peso): 1. Santo Antônio da Barra; 2. sulte sodica africana; 3. sulte potássica africana. Os dados das sultes sodica e potássica são de Sorensen (1974, p. 58), Hughes (1982, p. 323), Gerasimovsky \& Poliakov (1972, p. 36) e Bell \& Powell (1969, p. 549 e 550). Os símbolos são os mesmos da figura 3 


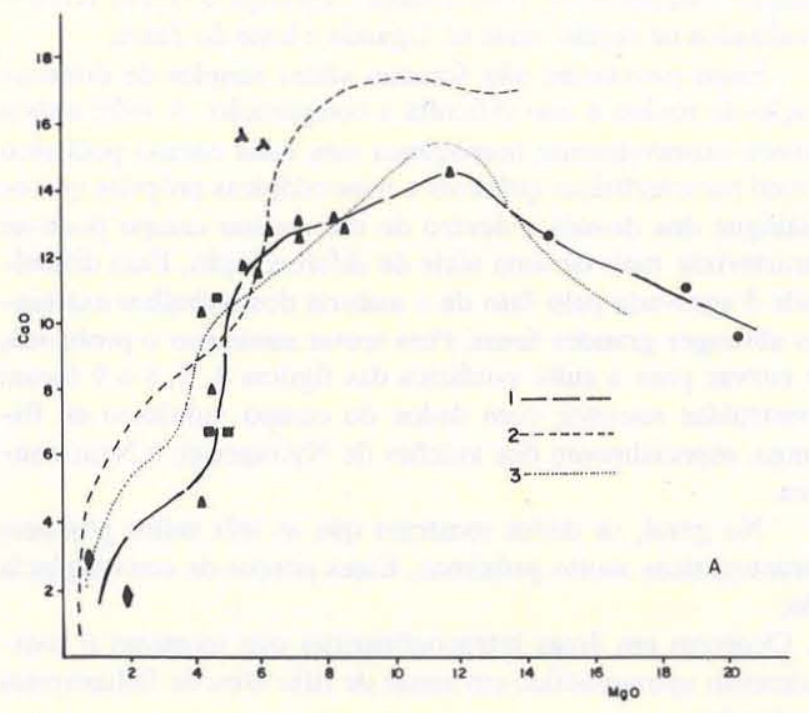

Figura 5 - Diagrama $\mathrm{CaO}$ × $\mathrm{MgO}$. Curvas 1,2 e 3 representativas para as suftes de Santo Antônio da Barra, sódica e potássica africanas, respectivamente. Os símbolos são os mesmos usados na figura 3 a diferenciação não parece ter sido linear e, provavelmente, estudos mineralógicos sistemáticos revelarão feições genéticas ainda desconhecidas ou pouco claras. Deve-se observar que os melilita mela-nefelinitos não foram considerados no traçado da curva de Santo Antônio da Barra.

$\mathrm{Na}$ figura 6 , onde são plotados os elementos menores versus o valor de $\mathrm{Mg}$, as seguintes observaçöes podem ser feitas:

- as rochas exibem empobrecimento em $\mathrm{Cr}, \mathrm{Ni}, \mathrm{V}$ e $\mathrm{Co}$ à medida que se diferenciam e o trend, a partir da olivina melaanalcimitos até os fonб́litos, é claro;

- da mesma forma, o trend pode ser visto para os elementos $\mathrm{Rb}$ e $\mathrm{Zr}$ que, ao contrário, tornam-se enriquecidos em direção aos termos mais diferenciados;

- Co, V e Rb mostram grande dispersão de valores nos melaanalcimitos. Os dois primeiros estão, provavelmente, associados a olivina e magnetita, respectivamente. $\mathrm{O}$ fato de $\mathrm{Rb}$ mostrar correlação positiva com alumina pode estar indicando sua associação com flogopita e sanidina (nos fonólitos);

- apesar dos altos valores de $\mathrm{Zr}$, nenhum mineral de zircônio foi identificado nas rochas estudadas. Taylor (1965, apud Nash et al. 1969) sugere que $\mathrm{Zr}^{+4}$ pode substituir $\mathrm{Ti}^{+4} \mathrm{e}$, desde que nenhum silicato de zircônio esteja presente, este pode ser concentrado em piroxênio tão bem como em vidro

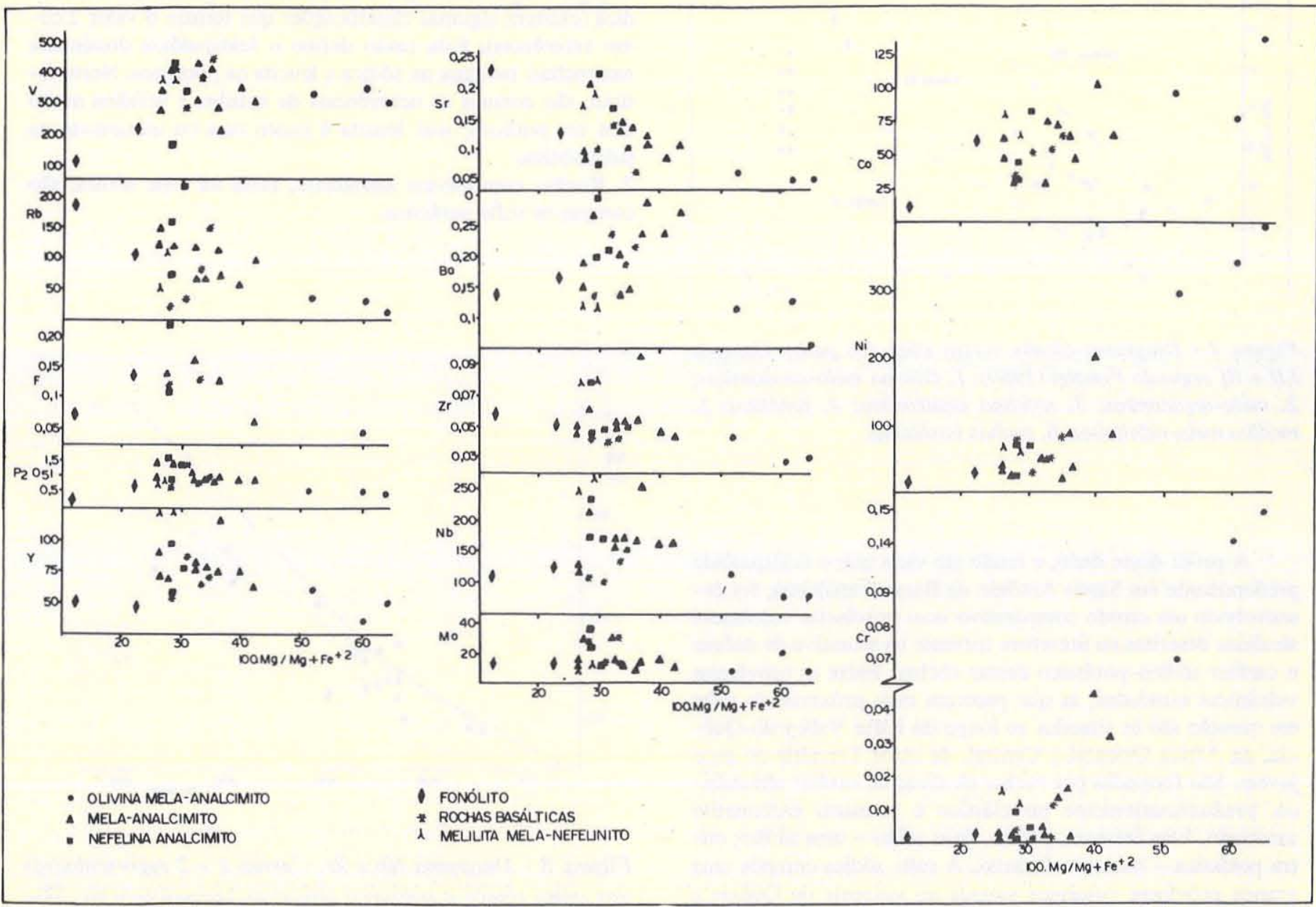

Figura 6 - Valor de Mg versus elementos menores e em traços. $\mathrm{V}, \mathrm{Rb}, \mathrm{Y}, \mathrm{Nb}$ e Mo são dados em ppm. Os demais em porcentagem. 
residual. Dawson (1982) considera perovskita e ilmenita como importantes fases hospedeiras de $\mathrm{Zr}$;

- F, P e Y concentram-se em direção aos nefelina analcimitos diminuindo consideravelmente nos fonólitos. Apatita é um importante receptor desses elementos e abundante nos nefelina analcimitos;

- $\mathrm{Sr}, \mathrm{Ba}$ e $\mathrm{Nb}$ mostram grande dispersão de valores, sugerindo que sua distribuição nos minerais não segue a linha de diferenciação magmática. Os altos teores de $\mathrm{Sr}$ e Ba são característicos desses tipos de rochas. A ausência de correlação entre esses elementos e o valor de $\mathrm{Mg}$ pode estar relacionada ao grande número de fases mineralógicas hospedeiras desses elementos; apatita, perovskita, clinopiroxênio, calcita e plagioclásio são importantes receptores de $\mathrm{Sr}$ e biotita e clinopiroxênio, de $\mathrm{Ba}$. Com exceção de clinopiroxênio, a distribuição desses minerais nas rochas não segue um padrão linear. Não menos importantes para a falta de correlação podem ter sido as transformaçōs tardi a pos-magmáticas.

Em relação à alcalinidade da suíte, o diagrama da figura 7 mostra os campos de Pouclet (1980) para as rochas subalcalinas a alcalinas e essencialmente feldspáticas (I), rochas alcalinas sరdicas ou potássicas com feldspato e fedspatóide (II) e rochas hiperalcalinas potássicas e per-potássicas essencialmente feldspatoídicas (III). As rochas de Santo Antônio da Barra concentram-se no campo II de Pouclet.

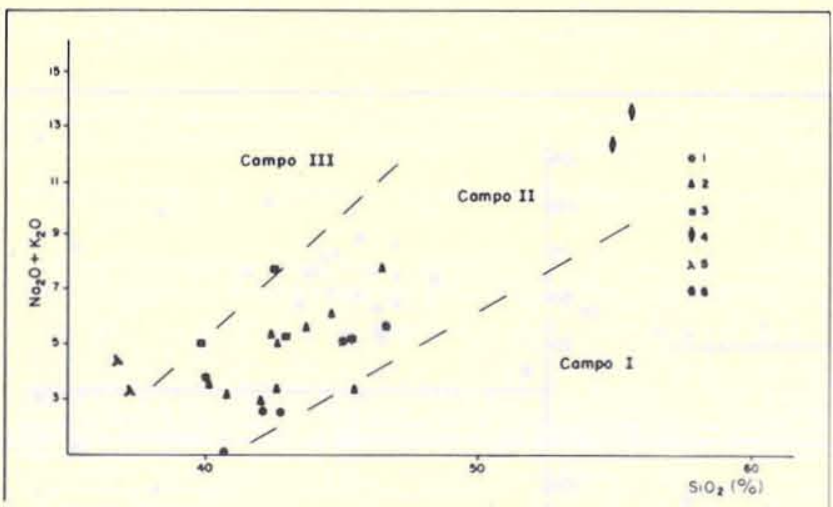

Figura 7 - Diagrama álcalis versus stlica (\% peso). Campos I,II e III segundo Pouclet (1980). 1. Olivina mela-analcimitos; 2. mela-analcimitos; 3. nefelina analcimitos; 4. fonólitos; 5. melilita mela-nefelinitos; 6. rochas basálticas

A partir desse dado, e tendo em vista que o feldspatoide predominante em Santo Antônio da Barra é analcima, foi desenvolvido um estudo comparativo com províncias vulcânicas alcalinas descritas na literatura corrente na tentativa de definir o caráter sódico-potássico dessas rochas. Entre as províncias vulcânicas estudadas, as que parecem mais próximas da suíte em questão são as situadas ao longo do Rifte Valley do Quênia, na África Oriental e Central, de idade Terciária ou mais jovem. São formadas por rochas alcalinas de caráter ultrabásico, predominantemente piroclástico e possuem carbonatito associado. Elas formam, porém, duas suítes - uma sódica, outra potássica - bastante distintas. A suíte sódica compõe uma grande província vulcânica situada no sudoeste do Quênia e leste de Uganda, onde Elgon, Napak, Kisingiri e Oldoynio Lengai são vulcões típicos. A potássica ê formada por três campos vulcânicos - Toro Ankole, Birunga e South Kivu localizados na região oeste de Uganda e leste do Zaire.

Essas províncias não formam séries simples de diferenciação de rochas e isso dificulta a comparação. A suíte sódica parece razoavelmente homogênea mas cada campo potássico possui características químicas e mineralogicas próprias que os distingue dos demais e dentro de um mesmo campo pode-se caracterizar mais de uma série de diferenciação. Essa dificuldade é agravada pelo fato de a maioria dos trabalhos existentes abranger grandes áreas. Para tentar minimizar o problema, as curvas para a suíte potássica das figuras 4, 5, 8 e 9 foram construídas somente com dados do campo vulcânico de Birunga, especialmente dos vulcões de Nyiragongo e Nyaramugira.

No geral, os dados mostram que as três suítes possuem características muito próximas. Esses pontos de convergência são:

1. Ocorrem em áreas intracontinentais que mostram o soerguimento epirogenético em zonas de rifte e/ou de falhamentos profundos.

2. O vulcanismo ê altamente explosivo indicando riqueza em voláteis.

3. Estão associadas a carbonatitos.

4. Clinopiroxênio é o fenocristal dominante.

5. São insaturadas em sílica e ricas em $\mathrm{CaO}$.

6. Possuem valores altos de $\mathrm{Ti}, \mathrm{Sr}, \mathrm{Ba}$ e $\mathrm{Zr}$.

No entanto, as suítes africanas possuem algumas diferenças importantes que as distinguem (ver também as curvas apresentadas nas figuras 4, 5, 8 e 9):

1. $\mathrm{K}_{2} \mathrm{O} / \mathrm{Na}_{2} \mathrm{O}$ maior que 1 na potássica e menor que 1 na sбdica (existem algumas classificações que tomam o valor 2 como referência). Esta razão define o feldspatóide dominante nas rochas: nefelina na sódica e leucita na potássica. Neste último, são comuns as ocorrências de kalsilita e nefelina muito rica em potássio, mas leucita é muito rara ou inexistente na suíte sódica.

2. Rochas com olivina abundante, raras na suíte sర́dica, são comuns na suíte potássica.

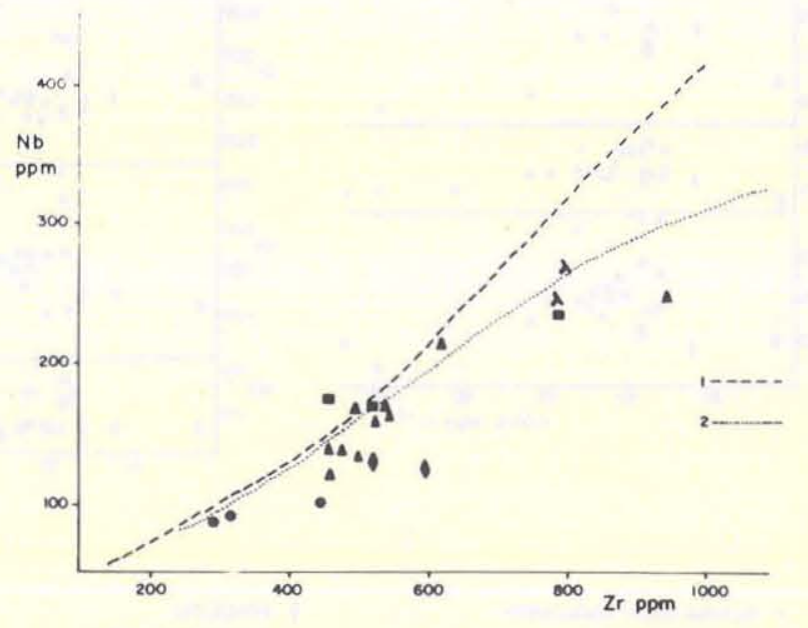

Figura 8 - Diagrama $\mathrm{Nb}$ x Zr. Curvas 1 e 2 representativas das sultes sódica e potássica africanas, respectivamente. Símbolos conforme figura 3. Os dados utilizados são os mesmos citados na figura 4 (além de Le Bas 1979, para a sulte sódica) 
3. Ocorrência bastante freqüente, embora localizada, de rochas com plagioclásio cálcico (basanitos, tefritos, álcali-basaltos) na suíte potássica (Gupta \& Yagi 1980). Essas rochas são praticamente ausentes na suíte sódica.

4. De modo geral, $\mathrm{Fe}^{+3}$ predomina sobre $\mathrm{Fe}^{+2}$ na suíte sodica e vice-versa na potássica.

5. Apesar de $\mathrm{Ti}, \mathrm{Sr}, \mathrm{V}, \mathrm{Cr}$ e Ni mostrarem valores altos nas duas suítes, eles são, em média, mais altos na suíte potássica.

Para a suíte em questão, observa-se que, enquanto fonólitos, nefelina analcimitos e alguns mela-analcimitos mostram razăo $\mathrm{K}_{2} \mathrm{O} / \mathrm{Na}_{2} \mathrm{O}>1$, para os olivina mela-analcimitos, para as rochas basálticas e a maioria dos mela-analcimitos esta razão é menor que 1 . As curvas apresentadas nas figuras 4, 5, 8 e 9 mostram a consonância existente na distribuição de $\mathrm{Mg}$, $\mathrm{Ca}, \mathrm{Al}, \mathrm{Ni}$ e $\mathrm{Zr}$ nas rochas das suítes potássica africana e de Santo Antônio da Barra. A suíte sódica distingue-se principalmente em relação ao comportamento de $\mathrm{Mg}$, Ca e $\mathrm{Zr}$. Além disso, as rochas de Santo Antônio da Barra concentram-se nos intervalos de 100 e 200 ppm de $\mathrm{Nb}$ e 400 e 600 ppm de $\mathrm{Zr}$. O fonólitos desta suíte, assim como as rochas mais diferenciadas da suítes potássica, localizam-se também neste intervalo e são menos enriquecidas em $\mathrm{Nb}$ que os fonólitos da suíte sódica (que possuem valores acima de 200 ppm). Os valores de $\mathrm{Ni}$ decrescem rapidamente com a diferenciação a valores de $\mathrm{Zr}$ quase constantes (Fig. 9).

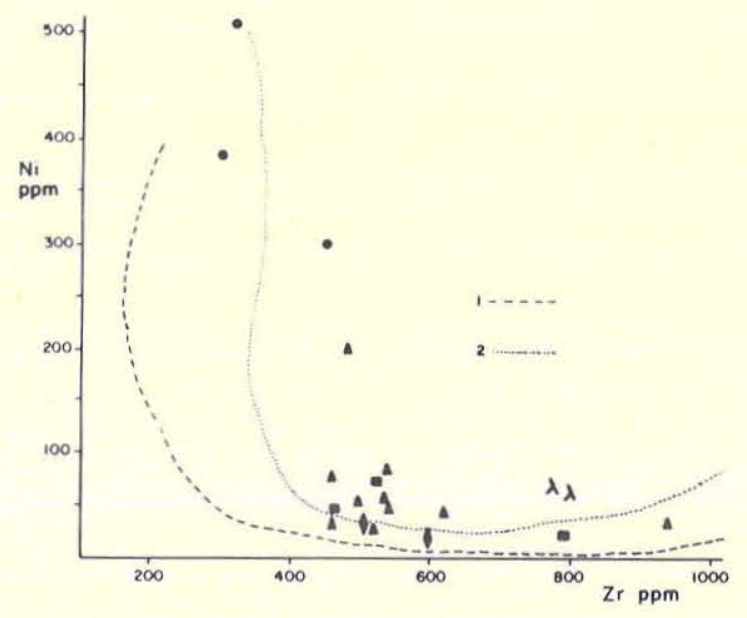

Figura 9 - Diagrama Nix Zr. Curvas 1 e 2 representativas das suftes sódica e potássica africanas, respectivamente. Símbolos conforme figura 3. Os dados utilizados são os mesmos citados na figura 8

Apesar desses dados, o gráfico da figura 10 reforça o caráter sódico-potássico misto da suíte de Santo Antônio da Barra. Essa constatação reabre a discussão sobre a origem primária ou secundária da analcima; a confirmação definitiva de origem secundária - hipótese adotada pela autora com base nos dados químicos apresentados e na discussão acima - explicaria o caráter misto da suíte pela troca de $\mathrm{K}$ por $\mathrm{Na}$ na transformação de leucita para analcima.

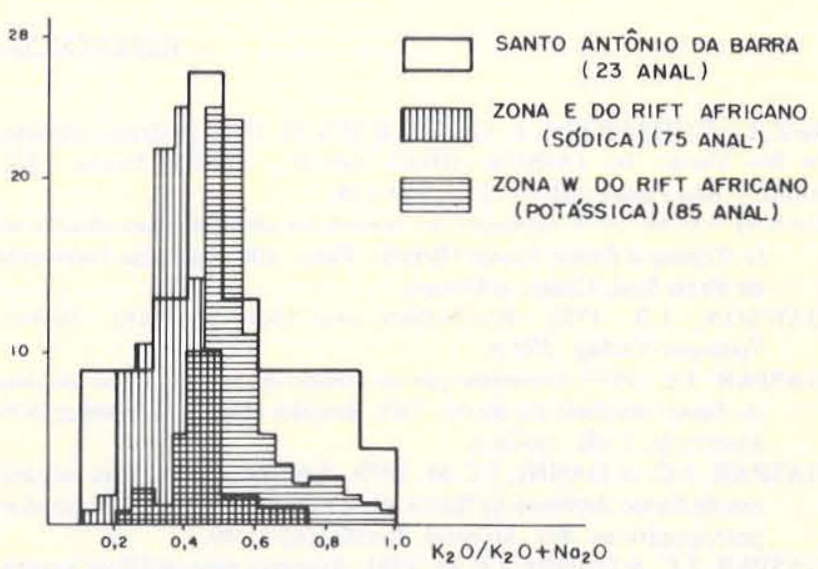

Figura 10 - Histograma $\mathrm{K}_{2} \mathrm{O} / \mathrm{K}_{2} \mathrm{O}+\mathrm{Na}_{2} \mathrm{O}$. Os dados das sultes sódica e potássica africanas são de Gerasimovsky \& Polyakov (1972)

Outrossim, apesar de suas afinidades claras com a suíte po=tássica africana - já apontada por Bez \& Guimarães (1971) mas revista por Gaspar (1977), que a considera sódica - não possui termos como mafurito (kalsilita, augita, olivina) ou katungito (olivina, melilita, leucita), típicos daquela. Este fato é favorável a algumas opiniōes em recentes discussões sobre a existência de uma manto heterogêneo.

CONCLUSÕES As rochas ígneas de Santo Antônio da Barra formam uma suíte alcalina insaturada com respeito a sílica, de tendência ultrabásica, com teores de álcalis variando de $0,66 \%$ a $13,74 \%$. Tanto a petrografia como a petroquímica evidenciam um trend de diferenciação que é: olivina melaanalcimito, mela-analcimito, nefelina analcimito, fonбlito. As relações entre este trend $\mathrm{e}$ os outros termos petrográficos presentes na área são ainda obscuras. As características e relações mineralógicas e petrográficas sugerem que a evolução magmática não foi simples e linear. Os dados petroquímicos reforçam essa idéia.

A analcima foi caracterizada por Gaspar \& Danni (1979), que adotam a hipótese de origem primária para este mineral. As tentativas para caracterizar restos de leucita, feitas pela autora, foram infrutíferas. No entanto, as análises químicas das rochas de Santo Antônio da Barra assim como sua afinidade com a suíte potássica do rifte oriental africano sugerem fortemente um caráter potássico primário para a suíte em questão. Essa hipótese implica processo de analcimização secundário, isto é, a analcima seria produto da alteração de leucita.

Agradecimento A autora é sinceramente grata ao professor Dr. José C.M. Danni, orientador da dissertação de Mestrado que deu origem a este trabalho. 


\section{REFERÊNCIAS BIBLIOGRÁFICAS}

BEZ, L.; GUIMARÃES, J.; GUIMARÃES, D. 1971. Distrito vulcânico de Rio Verde. In: CONGR. BRAS. GEOL., 25, São Paulo, 1971. Anais... São Paulo, SBG v. 2. p. 121-128.

DANNI, J.C.M. 1974. Géologie des complexes ultrabasiques alcalins de la Regina d'Iporá, Goiás (Brésil). Paris. 104 p. (Thèse Université de Paris Sud, Centre d'Orsay).

DAWSON, J.B. 1982. Kimberlites and their xenoliths. Berlim. Springer-Verlag. $250 \mathrm{p}$

GASPAR, J.C. 1977. Contribuição ao estudo do magmatismo alcalino de Santo Antônio da Barra, GO. Brasília. 143 p. (Dissertação de Mestrado, UnB, inédito).

GASPAR, J.C. \& DANNI, J.C.M. 1979. Analcima nas rochas vulcânicas de Santo Antônio da Barra, Goiás, e suas possíveis implicações petrogenéticas. Bol. Mineral, Recife, (6):41-49.

GASPAR, J.C. \& DANNI, J.C.M. 1981. Aspectos petrográficos e vulcanológicos da província alcalina-carbonatítica de Santo Antônio da Barra, sudoeste de Goiás. Rev. Bras. Geoc., 11(1):74-86.

GERASIMOVSKI, V.I. \& POLYAKOV, A.L. 1972. Alkaline rocks of the East Africa Rift Zones (Geochemistry and genesis). In. INTER. GEOL. CONGR., 24, Montreal, 1972. Proceed... Montreal, Int. Min. Assoc. p. 34-40(section 14 - Mineralogy).

GUPTA, A.K. \& YAGI, K. 1980. Petrology and genesis of leucite bearing rocks. Berlim, Springer-Verlag. $251 \mathrm{p}$.

HASUI, Y.; DYER, R.C.; IWANUCH, W. 1971. Geocronologia das rochas alcalinas de Santo Antônio da Barra, GO. In: CONGR. BRAS. GEOL. 25, São Paulo, 1971. Anais... São Paulo, SBG.v. 1. p. 253-258.
KESSON, S.E. 1973. The primary geochemistry of the Monaro alkaline volcanics, southeastern Australia - evidence for upper mantle heterogeneity. Contrib. Mineral. Petrol., 42:93-108.

LES BAS, M.J. 1977. Carbonatite-nephelinite volcanism. London, Willey, $374 \mathrm{p}$.

LE BAS, M.J. 1978. Are olivine-poor nephelinites a primary melt product from the mantle? Bull. volcanol., 41(4):463-465.

LIPPARD, S.J. \& TRUCKLE, P.H. 1972. Spatial and temporal variatons in basalt geochemistry in the N. Kenya Rift. Tectonophysics, 15:123-131.

MORAES, L.C. 1984. Petrologia, estratigrafia e potencial diamantífero da suite vulcânica alcalina da região de Santo Antônio da Barra, Goiás. Brasília. 122 p. (Dissertação de Mestrado. UnB).

NASH, W.P.; CARMICHAEL, I.S.E.; JOHNSON, R.W. 1969. Mineralogy and petrology of Mount Suswa, Kenya. J. Petrol., 10:409. 439.

POUCLET, A. 1980. Contribution à la systématique des laves alcalines, les laves du rift de l'Afrique Centrale (Zaire-Uganda). Bull. Volcanol., 42:527-537.

WASS, S.Y. \& ROGERS, N.W. 1980. Mantle Metassomatism-precursor to continental alkaline volcanism. Geoch. Cosmoch. Acta, 44:1811-1823.

MANUSCRITO 461

Recebido em 07 de maio de 1987 Revisão em 30 de outubro de 1987

A vocação primordial da universidade ê de cuidar da eficiência da educaçăo, associando sempre a pesquisa à transmissảo e ao aprofundamento dos conhecimentos fundamentais ligados ao desenvolvimento científico e técnico de uma sociedade responsável, cuja riqueza demográfica não pode ser aviltada, sob pena de se tornar perigosa e insustentável. A manutenção dessa riqueza exige o amparo e o aproveitamento de todos os indivíduos harmonizando o saber, o fazer e o ser.

Paul Arbousse-Bastide, 1984, O que o Brasil me ensinou. (Aula Magna proferida na USP). 